\title{
Reproducibility and Repeatability of Measures of Milk Coagulation Properties and Predictive Ability of Mid-Infrared Reflectance Spectroscopy
}

\author{
R. Dal Zotto, ${ }^{1}$ M. De Marchi, A. Cecchinato, M. Penasa, M. Cassandro, P. Carnier, L. Gallo, and G. Bittante \\ Department of Animal Science, University of Padova, Viale dell'Università 16, 35020 Legnaro, Padova, Italy
}

\begin{abstract}
The objectives of the study were to estimate the reproducibility and repeatability of milk coagulation properties (MCP) measured by a computerized renneting meter (CRM) and to evaluate the predictive ability of mid-infrared spectroscopy (MIRS) as an innovative technology for the assessment of rennet coagulation time (RCT, min) and curd firmness $\left(\mathrm{a}_{30}, \mathrm{~mm}\right)$. Four samples without addition of preservative (NP) and 4 samples with Bronopol addition (PS) were collected from each of 83 Holstein-Friesian cows. Six hours after collection, 2 replicated measures of MCP were obtained with CRM using $1 \mathrm{NP}$ and 1 PS sample from each cow. Mid-infrared spectra of the remaining NP and PS samples from each animal were recorded after $6 \mathrm{~h}, 4 \mathrm{~d}$, and $8 \mathrm{~d}$ after sampling. Two groups of calibration equations were developed using MIRS spectra and CRM measures of MCP as reference data obtained from analysis of NP and PS, respectively. Reproducibility and repeatability of CRM measures were obtained from REML estimation of variance components on the basis of a linear model including the fixed effects of herd and days in milk class and the random effects of cows, sample treatment (addition or no addition of preservative), and the interaction between cow and sample treatment. Coefficient of reproducibility is an indicator of the agreement between 2 measurements of MCP for the same milk sample preserved with or without addition of Bronopol. Coefficient of repeatability is an indicator of the agreement between repeated measures of MCP. Pearson correlations between MCP measures for NP and PS were 0.97 and 0.83 for RCT and $\mathrm{a}_{30}$, respectively. Reproducibility of CRM measures under different preserving conditions of milk was $93.5 \%$ for RCT and $64.6 \%$ for $\mathrm{a}_{30}$. Repeatabilities of RCT and $\mathrm{a}_{30}$ measures were 95.7 and $77.3 \%$, respectively. Based on the estimated cross-validation standard errors and coefficients of determination and ratios of standard
\end{abstract}

Received October 12, 2007.

Accepted June 11, 2008.

${ }^{1}$ Corresponding author: riccardo.dalzotto@unipd.it errors of cross-validation to standard deviation of reference data, the predictive ability of MIRS calibration equations was moderate for RCT and unsatisfactory for $\mathrm{a}_{30}$. Predictive ability of equations based on spectra and MCP measures of PS was greater than that of equations based on data of NP. The study did not provide conclusive evidence on the effectiveness of MIRS as a predictive tool for MCP and it requires an enlargement of the variability of milk sampling circumstances. Because the relevance of MIRS predictions in relation to breeding programs for MCP based on indicator traits relies on the genetic variation of MIRS predictions and on phenotypic and genetic correlations between MIRS predictions and MCP measures, additional specific investigations on these topics are needed.

Key words: milk coagulation properties, repeatability, reproducibility, mid-infrared spectroscopy

\section{INTRODUCTION}

The coagulation ability of milk plays an important role in cheese production. This characteristic is particularly relevant for countries such as Italy where large amounts of milk are used for cheese making and for manufacturing of typical products (e.g., ParmigianoReggiano, Grana Padano, Pecorino Romano, and Mozzarella Campana). The efficiency of milk processing is influenced by its chemical and physical properties, production technology, and cheese-maker experience. Casein content and milk coagulation properties (MCP) are crucial factors in the cheese-making process (Ikonen et al., 2004). Milk coagulation properties are the outcome of interactive effects involving several aspects affecting the milk coagulation process, such as variants of the $\mathrm{K}$-casein (Mariani et al., 1976) and B-lactoglobulin genes (Kübarsepp et al., 2005), titratable acidity (Summer et al., 2002) and $\mathrm{pH}$ (Lindström et al., 1984), calcium content (Tervala et al., 1985; Kübarsepp et al., 2005), and breed (De Marchi et al., 2007). Because exploitable additive genetic variation seems to exist for MCP (Ikonen et al., 1997, 1999; Cassandro et al., 2008), genetic improvement of MCP could be an effective way to enhance the efficiency of cheese production (Ikonen, 2000). 
Currently, assessment of MCP can be performed through milk coagulation meters, which provide measures of milk rennet clotting time (RCT, min) and curd firmness $\left(\mathbf{a}_{30}, \mathbf{m m}\right)$. In addition to the fact that knowledge on reproducibility and repeatability of MCP measures is scarce, these methods have some unfavorable features: measurement is time consuming (31 min per analysis) and skilled personnel are required. For these reasons, the routine assessment of MCP for all cows involved in milk recording programs is practically unfeasible and, therefore, sire evaluation programs would need to be limited to a random sample of offspring per sire with unfavorable effects on accuracy of EBV.

Because of the high throughput (potentially hundreds of samples/hour; Foss, 2007), ease of use, and reduced cost of analysis (Soyeurt et al., 2006), midinfrared reflectance spectroscopy (MIRS) may be a possible alternative technique for the assessment of $\mathrm{MCP}$, if the accuracy of the measurements is satisfactory. Mid-infrared reflectance spectroscopy has been implemented in the measurement of milk protein content (Etzion et al., 2004) and milk composition (Lynch et al., 2006), the assessment of fatty acid contents in milk (Soyeurt et al., 2006), the prediction of sensory texture and chemical traits of processed cheese (Karoui et al., 2006; Fagan et al., 2007), and the quantification of acetone in milk for the detection of subclinical ketosis (Heuer et al., 2001). Currently, however, studies on the application of MIRS techniques for the measurement of MCP are not available.

The aims of this study were to estimate the repeatability of MCP measured by using a computerized renneting meter (CRM) to evaluate the reproducibility of MCP measures under different storage conditions of milk samples and to investigate the applicability of MIRS as a new technique for the assessment of MCP.

\section{MATERIALS AND METHODS}

\section{Sample Collection and Storing Procedures}

Individual 400-mL milk samples were collected from 83 Holstein-Friesian cows [milk yield (mean $\pm \mathrm{SD}$ ): 30.9 $\pm 7.6 \mathrm{~kg} / \mathrm{d}$; milk fat: $3.85 \pm 0.78 \%$; milk protein: $3.26 \pm$ $0.34 \%]$ reared in 3 herds. Milk sampling occurred on the same day for all cows milked in a herd.

Immediately after collection, each individual milk sample was partitioned into 8 subsamples of $50 \mathrm{~mL}$ each. Four subsamples of each cow (PS subsamples) were processed according to International Committee for Animal Recording procedures (ICAR, 2006) and combined with preservative (Bronopol, Knoll Pharmaceuticals, Nottingham, UK); the remaining 4 subsamples (NP subsamples) were stored with no preser- vative. All PS subsamples of a cow were refrigerated at $4^{\circ} \mathrm{C}$ : 2 subsamples for $6 \mathrm{~h}\left(\mathbf{P S}_{0}\right.$ : 1 subsample used for CRM analysis and 1 used for MIRS assessment), 1 subsample for $4 \mathrm{~d}$ ( $\mathbf{P S}_{4}$, for MIRS assessment), and 1 subsample for $8 \mathrm{~d}$ ( $\mathbf{P S}_{8}$, for MIRS assessment) following collection. Two NP subsamples were refrigerated at $4^{\circ} \mathrm{C}$ for $6 \mathrm{~h}\left(\mathbf{N P}_{\mathbf{0}}\right): 1$ subsample used for CRM analysis and 1 for MIRS assessment, whereas the remaining 2 $\mathrm{NP}$ were frozen and stored at $-18^{\circ} \mathrm{C}$ for MIRS analysis carried out $4\left(\mathbf{N P}_{4}\right)$ or $8 \mathrm{~d}\left(\mathbf{N P}_{8}\right)$ after collection, respectively. Milk samples of 4 cows did not coagulate within $31 \mathrm{~min}$, were classified as not coagulating according to the approach of Ikonen et al. (1999), and were discarded from the study. Several environmental factors (e.g., parity, lactation stage, season, feeding, and management practices) can lead to noncoagulated samples as reported by Ikonen et al. (2004) and Tyrisevä et al. (2004). Studies comparing individual milk samples have shown that MCP is also affected by physical and chemical parameters such as titratable acidity (Formaggioni et al., 2001), SCC (Politis and Ng-Kwai-Hang, 1988), protein and casein contents, and calcium and phosphorus concentrations (Summer et al., 2002).

\section{Analysis of MCP}

In this study, analysis of MCP using a CRM (Polo Trade, Monselice, Italy) was considered the reference method for the assessment of RCT and $\mathrm{a}_{30}$. The CRM is based on the swing of a pendulum driven by an electromagnetic field. During the milk coagulation process, differences in the electromagnetic field are recorded. After the addition of the clotting enzyme, coagulation takes place and the swing of the pendulum becomes smaller because of the enhanced curd firmness (Figure $1)$. This tool is often used as reference method to monitor MCP (Ikonen et al., 2004; Cassandro et al., 2008).

Analyses for the assessment of MCP through CRM were carried out at the Milk Quality Lab of the Veneto Agricoltura Institute (Thiene, Italy) and occurred within $6 \mathrm{~h}$ of milk sampling. Milk samples were heated to $35^{\circ} \mathrm{C}$ (Ikonen et al., 2004; Cassandro et al., 2008) in 3 to $4 \mathrm{~min}$; once $35^{\circ} \mathrm{C}$ was reached, $200 \mu \mathrm{L}$ of rennet (Hansen standard 190, Pacovis Amrein AG, Bern, Switzerland) was added and diluted $1.6 \%$ with distilled water. Measurements of MCP ended 31 min after the addition of the clotting enzyme. Measured traits were $\mathrm{RCT}$ (the time interval in minutes from the addition of the clotting enzyme to the beginning of coagulation) and $\mathrm{a}_{30}$ (the width in millimeters of the diagram 31 min after expressing the firmness of the curd; Ikonen et al., 2004; Figure 1). Only $\mathrm{NP}_{0}$ and $\mathrm{PS}_{0}$ milk samples were analyzed through CRM and each analysis was performed in duplicate. The $\mathrm{pH}$ was measured once 


\section{1 min usual cutting point of the curd}
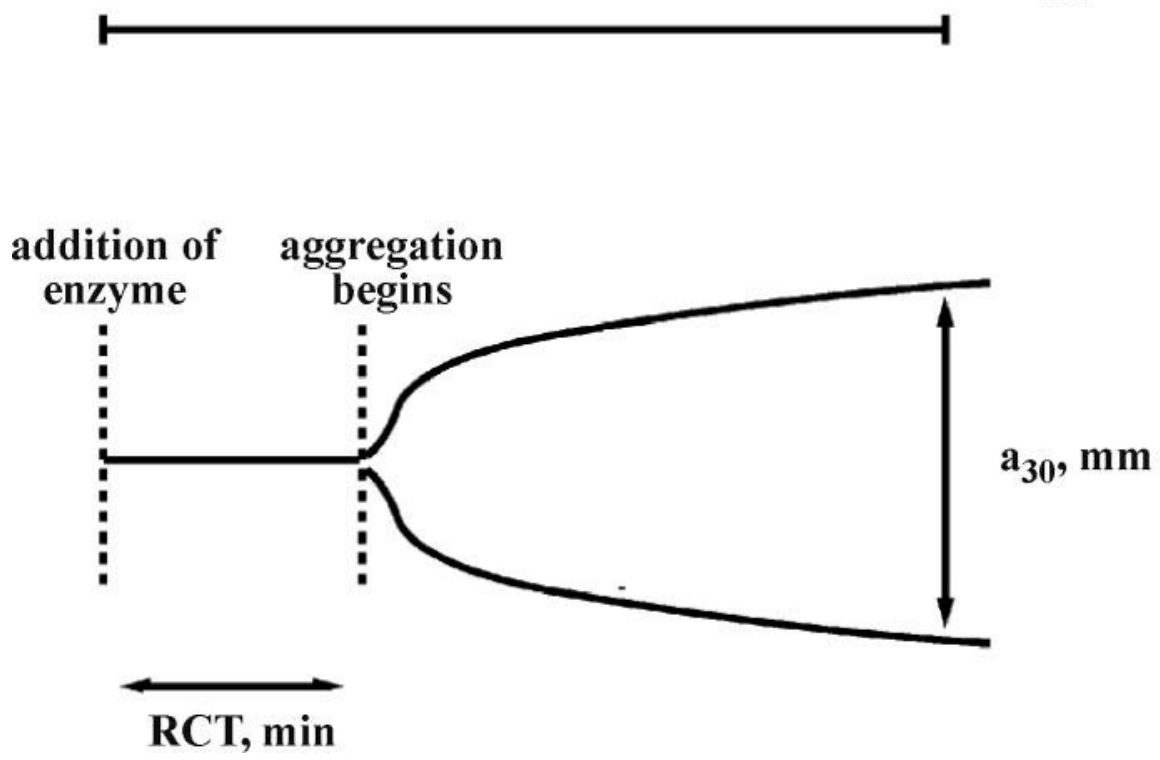

Figure 1. Diagram for normally coagulating milk sample produced by computerized renneting meter. The milk coagulation properties calculated from the diagram are milk coagulation time (RCT) in minutes and curd firmness $\left(\mathrm{a}_{30}\right)$ in millimeters (modified from Ikonen et al., 2004).

before heating milk samples, and not in samples with added preservative.

\section{MIRS}

A total of 474 milk samples (6 samples per cow: $\mathrm{NP}_{0}, \mathrm{NP}_{4}, \mathrm{NP}_{8}, \mathrm{PS}_{0}, \mathrm{PS}_{4}$, and $\mathrm{PS}_{8}$ ) were analyzed using MIRS. All MIRS analyses were carried out at the Milk Quality Lab of Veneto Agricoltura Institute (Thiene, Italy) using a MilkoScan FT120 (Foss, 2007), which scans the medium infrared region from 4,000 to $900 \mathrm{~cm}^{-1}$ and uses an interferometer. Spectra are generated from the resulting interferogram by means of fast Fourier transformations (Figure 2). The spectra were automatically recorded in duplicate in a database (Foss, 2007). The resulting spectral data were stored as $\log (1 / R)$, where $R$ are reflectance values, using WINISI II version 1.02 software (InfraSoft International, Port Matilda, PA).

\section{Estimation of Reproducibility and Repeatability of MCP}

Variance components for RCT and $\mathrm{a}_{30}$ measures obtained using CRM were estimated with the MIXED procedure of SAS (SAS Institute, 2001) based on the following mixed linear model:

$$
\begin{gathered}
\mathrm{y}_{\mathrm{ijklm}}=\mu+\mathrm{H}_{\mathrm{i}}+\mathrm{D}_{\mathrm{j}}+\mathrm{COW}_{\mathrm{k}: \mathrm{ij}}+\mathrm{P}_{1} \\
+(\mathrm{P} \times \mathrm{COW})_{\mathrm{kl}: \mathrm{ij}}+\mathrm{e}_{\mathrm{ijklm}}
\end{gathered}
$$

where $\mathrm{y}_{\mathrm{ijklm}}$ is a RCT or $\mathrm{a}_{30}$ measure provided by CRM for $\mathrm{NP}_{0}$ and $\mathrm{PS}_{0}$ samples; $\mu$ is the intercept; $\mathrm{H}_{\mathrm{i}}$ is the fixed effect of herd $(i=1, \ldots, 3)$; $D_{j}$ is the fixed effect of the stage of lactation $(j=1:<100 \mathrm{~d} ; \mathrm{j}=2$ : from 100 to $200 \mathrm{~d} ; \mathrm{j}=3:>200 \mathrm{~d}) ; \mathrm{COW}_{\mathrm{k}: \mathrm{ij}}$ is the random effect of the cow $(\mathrm{k}=1, \ldots, 79) ; \mathrm{P}_{1}$ is the random effect of the treatment ( $1=1$ : samples with no addition of preservative; 1 = 2: samples added with Bronopol preservative); $\mathrm{P} \times$ COW is the random effect of the interaction between treatment and cow; and $\mathrm{e}_{\mathrm{ijklm}}$ is a random residual. Animal (COW), treatment $(\mathrm{P})$, and $\mathrm{P} \times \mathrm{COW}$ effects, as well as residuals, were assumed to be independently and normally distributed with a mean of zero and variance $\sigma_{C O W}^{2}, \sigma_{P}^{2}, \sigma_{P \times C O W}^{2}$, and $\sigma_{e}^{2}$, respectively; REML was used as the method of estimation of variance components.

Reproducibility and repeatability were computed according to the guidelines suggested by the International Organization for Standardization (ISO, 1994a,b). In this study, definition of reproducibility differed from the standard one and aimed to evaluate the agreement between measures of MCP obtained using CRM under different preservation conditions of milk samples. Evaluation of reproducibility was based on 2 parameters: 1) reproducibility $(\mathbf{R D})$, defined as the value below which the absolute difference between 2 measures of MCP, obtained from the analysis of $\mathrm{NP}_{0}$ and $\mathrm{PS}_{0}$ subsamples of the same cow, respectively, and which is expected to lie within a probability of $95 \%$ (ISO, 1994a); and 2) coef- 


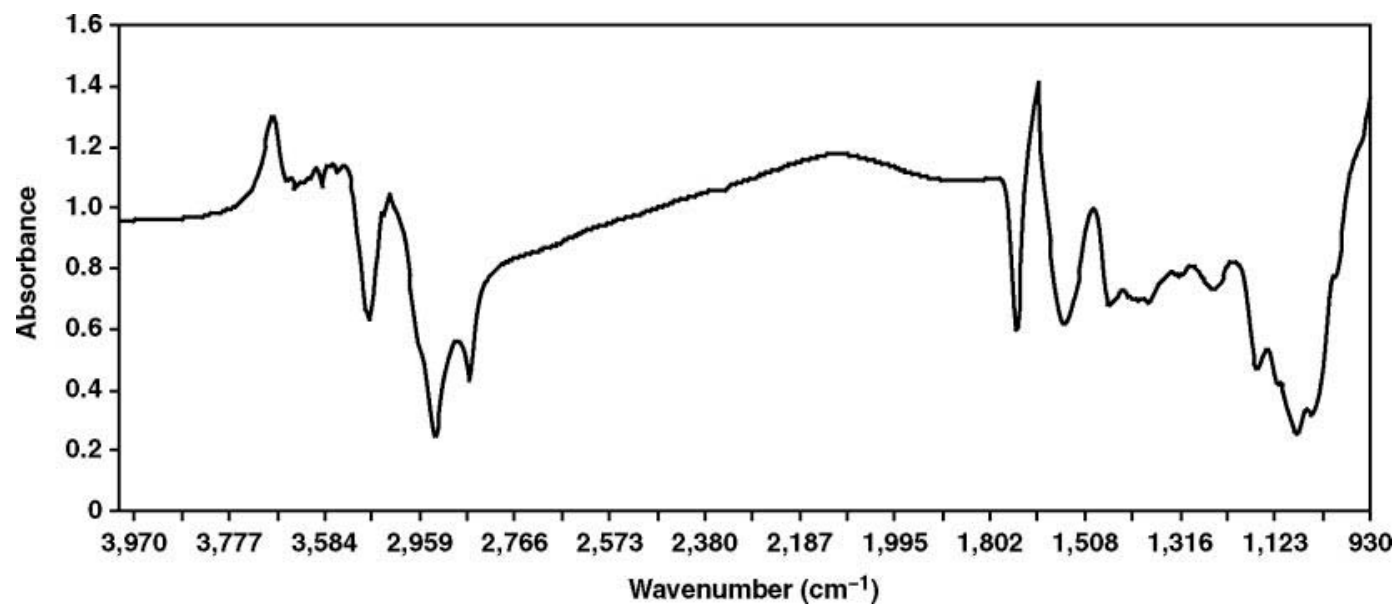

Figure 2. Example of untreated mid-infrared spectrum for milk.

ficient of reproducibility (RD\%), which is an indicator of the degree of agreement between 2 single measures of MCP for the same milk sample preserved with no addition or with addition of Bronopol preservative.

These parameters were computed as

$$
R D=2 \sqrt{2\left(\sigma_{P}^{2}+\sigma_{P \times C O W}^{2}+\sigma_{e}^{2}\right)}
$$

and

$$
R D \%=\frac{\sigma_{C O W}^{2}}{\sigma_{C O W}^{2}+\sigma_{P}^{2}+\sigma_{P \times C O W}^{2}+\sigma_{e}^{2}} \times 100 .
$$

Two statistical parameters were estimated to evaluate the repeatability of measures of MCP provided by CRM: 1) repeatability (RT), defined as the value below which the absolute difference between 2 single measures of MCP obtained by analyzing repeatedly, under the same conditions and within a short period, the same milk subsample $\left(\mathrm{NP}_{0}\right.$ or $\left.\mathrm{PS}_{0}\right)$, and which is expected to lie with a probability of $95 \%$ (ISO, 1994a); and 2) coefficient of repeatability (RT\%), which is an indicator of the degree of agreement between repeated measures of MCP obtained within a short period using CRM on the same milk subsample. Functions of estimated variance components were

$$
R T=2 \sqrt{2 \sigma_{e}^{2}}
$$

and

$$
R T \%=\frac{\sigma_{C O W}^{2}+\sigma_{P}^{2}+\sigma_{P \times C O W}^{2}}{\sigma_{C O W}^{2}+\sigma_{P}^{2}+\sigma_{P \times C O W}^{2}+\sigma_{e}^{2}} \times 100 .
$$

\section{MIRS Calibration Equations}

The software used for deriving the calibration was WINISI software, version 2. Calibration equations for MIRS were obtained using, as reference data, MCP measured by CRM on $\mathrm{NP}_{0}$ subsamples and 6 sets of data including spectra of $\mathrm{NP}_{0}, \mathrm{NP}_{4}, \mathrm{NP}_{8}, \mathrm{PS}_{0}, \mathrm{PS}_{4}$, and $\mathrm{PS}_{8}$ subsamples, respectively. Analysis of these sets of data provided 6 models to predict $\mathrm{MCP}$ of $\mathrm{NP}_{0}$ from spectra measured on $\mathrm{NP}_{0}, \mathrm{NP}_{4}, \mathrm{NP}_{8}, \mathrm{PS}_{0}, \mathrm{PS}_{4}$, and $\mathrm{PS}_{8}$ subsamples, respectively. To optimize calibration accuracy, the data were processed to a variety of derivative transformations using common mathematical treatments and scatter correction (Martens and Naes, 1989). The math treatment used was $0,0,1,1$, which refers to derivative, gap, smooth, smooth 2 , respectively. A derivative treatment of 0 means no derivative was used, a gap of 0 is the gap over which a derivative would be calculated, smooth 1 is the number of data points smoothed, and smooth 2 is a second smoothing operation, which is nearly always set to 1 .

All calibration regression models were estimated by modified partial least squares regression (Williams and Norris, 2001). Cross validation was performed during model development, wherein one-fourth of the population samples at a time were temporarily removed from the calibration set.

Samples with GH (Mahlanobis distance) and T (Student's $t$-distribution) values greater than 2.5 and 10 , respectively, were discarded, and the cycle was performed a second time, so the program removed outliers twice before completing the final calibration. The critical ' $\mathrm{T}$ ' is chosen by the operator to eliminate samples from the regression model. A value of 3 is conservative, 2 is liberal, and 2.5 is recommended. The critical ' $\mathrm{H}$ ' is chosen by the operator to eliminate samples with spectral distances too far from the population mean. A value 
Table 1. Descriptive statistics for milk rennet coagulation time (RCT, min) and curd firmness $\left(\mathrm{a}_{30}, \mathrm{~mm}\right)$ measured by computerized renneting meter

\begin{tabular}{lccccc}
\hline & \multicolumn{2}{c}{ Without preservative } & & \multicolumn{2}{c}{ With preservative $^{1}$} \\
\cline { 2 - 3 } \cline { 5 - 6 } Statistic & $\mathrm{RCT}$ & $\mathrm{a}_{30}$ & & $\mathrm{RCT}$ & $\mathrm{a}_{30}$ \\
\hline Mean & 15.24 & 36.13 & & 15.05 & 32.43 \\
SD & 3.99 & 8.44 & & 3.78 & 7.95 \\
Minimum & 9.10 & 17.00 & & 9.20 & 11.00 \\
Maximum & 25.70 & 55.00 & & 25.80 & 52.50 \\
\hline
\end{tabular}

${ }^{1}$ Samples with added Bronopol (Knoll Pharmaceuticals, Nottingham, UK).

of 10 is recommended. The critical ' $\mathrm{T}$ ' is chosen by the operator to eliminate samples with spectral distance too far from the population mean. The recommended value is 10 (Paulsen and Singh, 2004).

To assess the efficiency of the calibration equations, several statistical parameters were estimated: standard error of cross-validation (SECV) and cross-validation coefficient of determination $\left(R_{C V}^{2}\right)$ according to Haaland and Thomas (1988) and Martens and Naes (1989). To evaluate the efficiency of calibration equations for MCP prediction, the ratio of SECV to the standard deviation of reference data (RPD) and the ratio of SECV to the range of reference data were computed (RER; Williams and Norris, 2001). If RPD is $>2$, the calibration equation is considered good. On the other hand, if RPD ratio is $<1.5$, the predictions are of poor quality and the equation cannot be used in practice (Sinnaeve et al., 1994). The RER is useful for assessing the practical utility of predictive models. Models with an RER of $<3$ have little practical utility; RER values between 3 and 10 indicate limited to good practical utility, and $>10$ indicates that the model has a high utility value (Williams and Norris, 2001).

\section{RESULTS AND DISCUSSION}

\section{Descriptive Statistics and Correlations}

Descriptive statistics for MCP measured with CRM on milk samples preserved with no addition or with addition of preservative are in Table 1 . On average, RCT of samples preserved with the addition of Bronopol was slightly lower than that of samples with no preservative, whereas the average $a_{30}$ of PS samples exhibited a $10 \%$ decrease compared with that of NP samples. Variation of RCT and $\mathrm{a}_{30}$ was slightly affected by addition of preservative to milk samples: standard deviations of MCP were $6 \%$ smaller in PS than in NP samples and ranges of variation of RCT and $\mathrm{a}_{30}$ were similar for samples with added Bronopol and for milk without preservative. In general, RCT values observed in this study were similar to those reported by Summer et al. (1999) and Cassandro et al. (2008) for Italian Holsteins, but greater than those reported by Tyrisevä et al. (2004) and by Ikonen et al. (2004) for Finnish Ayrshire cows. These figures indicate a moderate cheese-processing aptitude of Holstein cattle milk when compared with MCP of milk from other dairy breeds (De Marchi et al., 2007).

Estimates of Pearson correlations for MCP measured by CRM on samples preserved with or without addition of Bronopol are reported in Table 2. For RCT, the correlation between samples without and with addition of preservative was $>0.95$ and greater than that for $\mathrm{a}_{30}$ $(\mathrm{r}=0.76 ; P<0.01)$, indicating that measures of RCT were less sensitive to different preserving conditions of milk samples than were measures of $\mathrm{a}_{30}$ and that the ranking of cows based on measured RCT would have been similar under different preserving circumstances of samples.

Consistent with findings of other studies (Ikonen et al., 2004; Cassandro et al., 2008), the correlations between $\mathrm{RCT}$ and $\mathrm{a}_{30}$ were negative $(P<0.01)$ and ranged from -0.78 to -0.71 . As time for instrumental assessment of MCP through current milk coagulation meters is restricted to $31 \mathrm{~min}$ from the addition of rennet to samples, less time is available for curd firmness for milk with a longer coagulation time, and, consequently, the final curd is weaker. Effects of milk preserving conditions on the estimated correlations between RCT and $\mathrm{a}_{30}$ measures were trivial.

Table 2. Pearson correlations $(P<0.001)$ for milk rennet coagulation time (RCT, min) and curd firmness $\left(\mathrm{a}_{30}, \mathrm{~mm}\right)$ measured by computerized renneting meter

\begin{tabular}{lccc}
\hline Trait $^{1}$ & $\mathrm{RCT}_{\mathrm{p}}$ & $\mathrm{a}_{30 \mathrm{w}}$ & $\mathrm{a}_{30 \mathrm{p}}$ \\
\hline $\mathrm{RCT}_{\mathrm{w}}$ & 0.968 & -0.776 & -0.708 \\
$\mathrm{RCT}_{\mathrm{p}}$ & & -0.733 & -0.746 \\
$\mathrm{a}_{30 \mathrm{w}}$ & & & 0.827 \\
\hline
\end{tabular}

${ }^{1} \mathrm{RCT}_{\mathrm{w}}$ and $\mathrm{a}_{30 \mathrm{w}}$ are measures obtained using milk samples without preservative; $\mathrm{RCT}_{\mathrm{p}}$ and $\mathrm{a}_{30 \mathrm{p}}$ are measures obtained using milk samples added with Bronopol preservative (Knoll Pharmaceuticals, Nottingham, UK). 
Table 3. Estimates of repeatability (RT), reproducibility (RD), coefficient of repeatability (RT\%), and coefficient of reproducibility (RD\%) for milk rennet coagulation time (RCT) and curd firmness $\left(\mathrm{a}_{30}\right)$ measured by computerized renneting meter

\begin{tabular}{lcc}
\hline Parameter $^{1}$ & RCT, min & $\mathrm{a}_{30}, \mathrm{~mm}$ \\
\hline Repeatability & & \\
RT & 2.04 & 11.81 \\
RT\%, \% & 95.7 & 77.3 \\
Reproducibility & & \\
RD & 2.50 & 14.73 \\
RD\%, \% & 93.5 & 64.6 \\
\hline
\end{tabular}

${ }^{1}$ Parameters: $R T=2 \sqrt{2 \sigma_{e}^{2}}, R T \%=\frac{\sigma_{C O W}^{2}+\sigma_{P}^{2}+\sigma_{P \times C O W}^{2}}{\sigma_{C O W}^{2}+\sigma_{P}^{2}+\sigma_{P \times C O W}^{2}+\sigma_{e}^{2}} \times 100$,

$R D=2 \sqrt{2\left(\sigma_{P}^{2}+\sigma_{P \times C O W}^{2}+\sigma_{e}^{2}\right.}$, and

$R D \%=\frac{\sigma_{C O W}^{2}}{\sigma_{C O W}^{2}+\sigma_{P}^{2}+\sigma_{P \times C O W}^{2}+\sigma_{e}^{2}} \times 100$, where $\sigma_{C O W}^{2}, \sigma_{P}^{2}, \sigma_{P \times C O W}^{2}$, and

$\sigma_{e}^{2}$ are variance components for cow, preservative, preservative $\times$

cow, and residual effects, respectively.

\section{Reproducibility and Repeatability of MCP Determined by CRM}

Estimates of reproducibility and repeatability for RCT and $\mathrm{a}_{30}$ are presented in Table 3. In this study, definition of reproducibility aimed to evaluate the agreement between measures of MCP obtained for the same sample under different preserving conditions of milk, rather than to evaluate the consistency of measures provided by different laboratories or operators. For measures of RCT, the estimated RD [i.e., the value below which the true absolute difference between 2 single measures, obtained with the same method of analysis applied to the same sample, but with different preserving conditions of milk (with or without addition of Bronopol) and different time of analysis], which is expected to lie within a $95 \%$ probability, was $2.5 \mathrm{~min}$ (i.e., $16 \%$ of average $\mathrm{RCT}$ ). For $\mathrm{a}_{30}$, the estimated $\mathrm{RD}$, being $43 \%$ of the trait average, was less favorable than for RCT.

Results obtained for $\mathrm{RD} \%$ were consistent with those obtained for RD. Again, measures of RCT were more reproducible under different preservation conditions of milk than were measures of $\mathrm{a}_{30}$. The estimated $\mathrm{RD} \%$ for RCT was $>90 \%$, indicating that the influence exerted by different preserving conditions of milk, interaction effects between preserving conditions and sample characteristics, and other residual effects not accounted for in the present study, on total variation of RCT measures was limited. Conversely, CRM measures of $\mathrm{a}_{30}$ were greatly affected by those sources of variation, which accounted for more than $35 \%$ of total variation of the trait; the agreement between measures provided by CRM for the same sample preserved with or without addition of Bronopol and repeated at different times was low. Because effects due to preserving conditions of samples and the interaction between preserving conditions and sample characteristics accounted for only $13 \%$ of variation of the trait, low reproducibility of $\mathrm{a}_{30}$ assessment was largely attributable to variation due to random and unexplainable differences between repeated measures made on the same sample.

The degree of agreement between repeated measures of MCP was different for RCT and $\mathrm{a}_{30}$. The estimated $\mathrm{RT}$ was 13 and $35 \%$ of the trait average for RCT and $\mathrm{a}_{30}$, respectively. For RCT, the estimate of RT\% was 0.96 and was in full agreement with the value of analytical repeatability reported by Caroli et al. (1990) for measures of RCT and $\mathrm{a}_{30}$ obtained using a formagraph. The estimated $\mathrm{RT} \%$ for $\mathrm{a}_{30}$ was unfavorable $(\mathrm{RT} \%=0.77)$ and not consistent with previous literature estimates (Caroli et al., 1990). Based on the estimated parameters, assessment of $\mathrm{a}_{30}$ with CRM should be performed with replicated analyses.

\section{Prediction of MCP using MIRS}

An example of a mid-infrared spectrum is shown in Figure 2. Curley et al. (1998) assigned protein to specific bands in the mid-infrared spectra of raw milk in the 1,570 to $1,550 \mathrm{~cm}^{-1}$ range. These results were confirmed by Etzion et al. (2004), Hewavitharana and Brakel (1997), and by Luginbühl (2002). Lipids are known to contribute to the region 3,000 to $2,800 \mathrm{~cm}^{-1}$, which accounts for the observed peaks at 2,928 and $2,855 \mathrm{~cm}^{-1}$ (Lefèvre and Subirade, 2000). The peak at $1,748 \mathrm{~cm}^{-1}$ can also be attributed to lipids.

Statistics of prediction results for RCT and $\mathrm{a}_{30}$ are presented in Tables 4 and 5. Calibration equations were estimated using CRM measures of MCP for samples without preservative as reference data and spectra measured at 0,4 , and $8 \mathrm{~d}$ from collection of milk samples. Hence, 6 different calibration equations were developed.

Mathematical treatments used were nonderivative, first derivative, and second derivative. A first derivative pretreatment offered improvement in model accuracy for all attributes; hence, those prediction results are shown. The math treatment used was $1,5,5,1$, which refers to derivative, gap, smooth, smooth 2 , respectively, for all models, with the exception of $1,5,5,4$ for $\mathrm{PS}_{8}$ samples with preservative (Tables 4 and 5). Samples that have GH and T values greater than 2.5 and 10 , respectively, may be classified as outliers. According to these criteria, a fraction of samples, which ranged from 5 to $14 \%$ of total data, were classified as outliers. 
Table 4. Statistics of number of samples, mathematical treatment, and prediction results for milk rennet coagulation time (RCT, min) using mid-infrared spectra

\begin{tabular}{|c|c|c|c|c|c|c|}
\hline \multirow[b]{2}{*}{ Parameter $^{1}$} & \multicolumn{3}{|c|}{ Samples without preservative ${ }^{2}$} & \multicolumn{3}{|c|}{ Samples with preservative ${ }^{3}$} \\
\hline & $\mathrm{NP}_{0}$ & $\mathrm{NP}_{4}$ & $\mathrm{NP}_{8}$ & $\mathrm{PS}_{0}$ & $\mathrm{PS}_{4}$ & $\mathrm{PS}_{8}$ \\
\hline Mathematical treatment ${ }^{4}$ & $1,5,5,1$ & $1,5,5,1$ & $1,5,5,1$ & $1,5,5,1$ & $1,5,5,1$ & $1,5,5,4$ \\
\hline SECV & 2.16 & 3.12 & 3.10 & 2.12 & 1.80 & 2.32 \\
\hline $\mathrm{R}_{\mathrm{CV}}^{2}$ & 0.64 & 0.41 & 0.29 & 0.63 & 0.73 & 0.55 \\
\hline Loadings, $\mathrm{n}$ & 6 & 4 & 4 & 8 & 8 & 8 \\
\hline
\end{tabular}

${ }^{1} \mathrm{SECV}=$ standard error of cross validation; $\mathrm{R}_{\mathrm{CV}}^{2}=$ coefficient of determination of cross validation; $\mathrm{RPD}=$ ratio of standard error of crossvalidation to standard deviation of reference data; RER = ratio of standard error of cross-validation to range of reference data.

${ }^{2}$ Samples without preservative reference data were measures of coagulation time provided by computerized renneting meter for $\mathrm{NP}_{0}$ samples without preservative; for samples with preservative, reference data were measures of coagulation time provided by computerized renneting meter for $\mathrm{PS}_{0}$ samples with preservative.

${ }^{3}$ Samples with preservative: samples added with Bronopol (Knoll Pharmaceuticals, Nottingham, UK) preservative; $\mathrm{PS}_{0}, \mathrm{PS}_{4}$, or PS ${ }_{8}=$ milk samples analyzed by mid-infrared reflectance spectroscopy 0,4 , or $8 \mathrm{~d}$ after collection, respectively; $\mathrm{NP}_{4}$ and $\mathrm{NP}_{8}$ samples with no preservative addition were frozen.

${ }^{4}$ Mathematical treatments: The first number denotes the derivative order, the second number denotes the number of nanometers in the segment used to calculate the derivative, the third and fourth numbers denote the number of data points over which running average smoothing was conducted.

For reference samples, mean (SD) of RCT (Table 4) ranged from 14.54 (3.59) to 14.81 (4.04) min for calibrations based on spectra measured on milk with no preservative and from 14.64 (3.43) to 14.72 (3.44) $\mathrm{min}$ for calibrations based on spectra of samples combined with Bronopol (data not shown). Therefore, variability of coefficients of variation for the 6 sets of reference samples was small and ranged from 23 to $27 \%$.
The preferred model for predicting RCT had a SECV value of $1.80 \mathrm{~min}$ and the corresponding RER value was 9.22. The accuracy of each model can be evaluated using the coefficients of determination $\left(\mathbf{R}^{2} \mathbf{c v}\right)$ between the predicted and measured values, as stated by Williams (2003). A value for $\mathrm{R}^{2} \mathrm{cv}$ between 0.50 and 0.65 indicates that discrimination between high and low values can be made. A value for $R^{2}$ cv between 0.66 and 0.81 indicates approximate quantitative predictions,

Table 5. Statistics of number of samples, mathematical treatment and prediction results for curd firmness ( $\mathrm{a}_{30}$, mm) using mid-infrared spectra

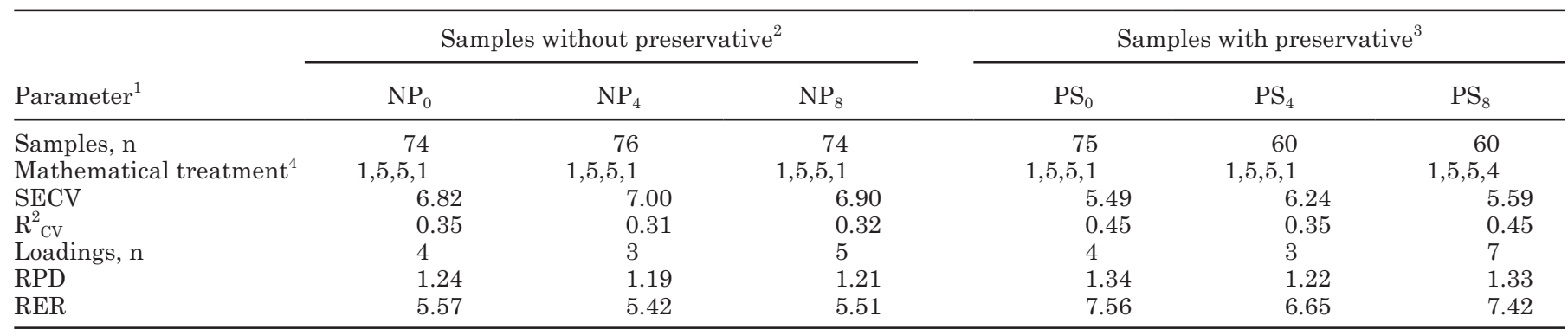

${ }^{1} \mathrm{SECV}=$ standard error of cross validation; $\mathrm{R}_{\mathrm{CV}}^{2}=$ coefficient of determination of cross validation; $\mathrm{RPD}=$ ratio of standard error of cross validation to standard deviation of reference data; RER = ratio of standard error of cross-validation to range of reference data.

${ }^{2}$ Samples without preservative reference data were measures of curd firmness provided by computerized renneting meter for $\mathrm{NP}_{0}$ samples without preservative; for samples with preservative, reference data were measures of curd firmness provided by computerized renneting meter for $\mathrm{PS}_{0}$ samples with preservative.

${ }^{3}$ Samples with preservative: samples with Bronopol (Knoll Pharmaceuticals, Nottingham, UK) preservative added; PS $_{0}$, PS $_{4}$, or PS $8=$ milk samples analyzed by computerized renneting meter 0 , 4 , or $8 \mathrm{~d}$ after collection, respectively; $\mathrm{NP}_{4}$ and $\mathrm{NP}_{8}$ samples with no preservative addition were frozen.

${ }^{4}$ Mathematical treatments: The first number denotes the derivative order, the second number denotes the number of nanometers in the segment used to calculate the derivative, the third and fourth numbers denote the number of data points over which running average smoothing was conducted. 
whereas a value for $R^{2}$ cv between 0.82 and 0.90 reveals good predictions. Models having a value for $\mathrm{R}^{2} \mathrm{cv}$ $>0.91$ are considered to be excellent (Williams, 2003). The RCT model $\left(\mathrm{R}^{2} \mathrm{cv}=0.73\right)$ allowed approximate quantitative predictions for RCT values, whereas for $\mathrm{a}_{30}$, the model $\left(\mathrm{R}^{2} \mathrm{cv}=0.45\right)$ did not allow any type of discrimination.

Moreover, high values for $\mathrm{R}^{2} \mathrm{cv}$ and RPD parameters are required for potential use of predictive equations. For RPD, values $>2$ indicate good calibrations and values $<1.5$ indicate unreliable predictions (Karoui et al., 2006). In this study, models with greater values of $\mathrm{R}^{2} \mathrm{cv}$ also had greater values of $\mathrm{RPD}$. This result is in agreement with results of Soyeurt et al. (2006), who observed a tight relationship between $\mathrm{R}^{2} \mathrm{cv}$ and RPD in a study aimed at estimating fatty acid content in cow's milk using MIRS.

As a general tendency, prediction equations for RCT (Table 4) based on spectra of samples preserved with Bronopol exhibited values of validation parameters more favorable than those estimated for calibrations using spectra of milk with no preservative. Values for RPD were very close to or greater than 1.5 for all predictive equations based on spectra of milk with addition of preservative, whereas, for calibrations based on samples with no addition of preservative, only the equation developed from spectra of samples providing reference data (i.e., $\mathrm{NP}_{0}$ subsamples) had $\mathrm{RPD}>1.5$. The only equation with RPD close to 2 and $R^{2} \mathrm{cv}>70 \%$ was that based on spectra measured on $\mathrm{PS}_{4}$ subsamples. Values for RER provided indications consistent with those from inspection of RPD estimates, suggesting that calibrations based on samples preserved with Bronopol had better practical utility. Although some of these results indicate that MIRS may have a role in the prediction of MCP, it is important to note that a critical aspect of this study was the development of prediction equations on the basis of reference samples collected in only 3 herds and over a very short period. Consequently, conclusive evidence on the effectiveness of MIRS as a predictive tool for MCP requires an enlargement of the variability of milk sampling circumstances.

Models for predicting $\mathrm{a}_{30}$ (Table 5) were unsatisfactory for both unpreserved and Bronopol-preserved milk samples. The $R^{2}$ cv values were low, ranging from 0.31 to 0.35 and from 0.35 to 0.45 , respectively; the estimated RPD were lower than 1.5 for all predictive equations; and RER values were less (from 5.51 to 7.56) than 10. As reported by Williams and Norris (2001), RER values of between 3 and 10 indicate limited to good practical utility.
It should also be noted that the loadings incorporated into the best RCT and $\mathrm{a}_{30}$ models were 8 and 4 , respectively (Tables 4 and 5). This is a relatively low number of loadings, which may provide high model robustness. To investigate a molecular basis for the prediction of MCP, the model loadings were examined (data not shown). The first 2 loadings of the models accounted for greater than $70 \%$ of the variation in the spectral data; however, it was difficult to assign functional groups to individual peaks. In fact, using spectra pretreated with a first derivative step, interpretation of the loadings associated with these models was difficult. This result was because the observed peaks and valleys did not follow the raw spectral pattern. Nevertheless, the regions of the spectra that seem to be important in predicting $\mathrm{RCT}$ and $\mathrm{a}_{30}$ were associated with the vibration of the $\mathrm{C}-\mathrm{H}, \mathrm{C}-\mathrm{O}$ bonds (from 1,200 to 1,000 $\left.\mathrm{cm}^{-1}\right)$, amide II $\left(1,540\right.$, and 3,900 to $\left.3,500 \mathrm{~cm}^{-1}\right)$, and lipids (from 2,900 to $1,700 \mathrm{~cm}^{-1}$ ). These results can be explained by the effects of milk protein and fat content on milk coagulation. Protein level significantly affects coagulation rate, including firming times (Fagan et al., 2008). Castillo et al. (2003) stated that increasing the protein content of milk decreases the curd firming time, whereas Dalgleish (1980) found that increasing the casein concentration by ultrafiltration resulted in a firmer final curd. Bastian et al. (1991) found that, although fat content had no effect on RCT, it did affect curd firming, with greater fat levels associated with firmer gels.

\section{CONCLUSIONS}

Results of this study indicate that the assessment of MCP through CRM provides repeatable and reproducible measures for RCT but not for $\mathrm{a}_{30}$. Addition of Bronopol preservative to milk samples makes routine application of CRM easier, with no detrimental effects on the reliability of RCT measures. This study was not able to provide positive conclusive evidence on the effectiveness of MIRS as a predictive tool for MCP. Hence, further investigations ensuring a larger variability of milk sampling circumstances are needed. For breeding programs aimed at enhancement of MCP, the low cost of analysis, high throughput, and the possibility of large-scale sampling make MIRS a potentially important alternative to CRM for measurement of MCP. However, the relevance of MIRS for programs focusing on selection for improved MCP based on indicator traits relies heavily on the genetic variation of MIRS predictions of MCP and on the magnitude of phenotypic and genetic correlation between MIRS pre- 
dictions and MCP. All of these aspects require specific investigations.

\section{ACKNOWLEDGMENTS}

The authors wish to thank Milk Quality Lab of Thiene (Italy) for the milk renneting analysis and Lorenzo Serva (GraiNit s.r.l., Padova, Italy) for support in MIRS analysis.

\section{REFERENCES}

Bastian, E. D., R. J. Brown, and C. A. Ernstrom. 1991. Plasmin activity and milk coagulation. J. Dairy Sci. 74:3677-3685.

Caroli, A., P. Bolla, G. Pagnacco, M. Rampilli, and L. Degano. 1990. Repeatability of milk clotting aptitude evaluated by lactodynamographic analysis. J. Dairy Res. 57:141-142.

Cassandro, M., A. Comin, M. Ojala, R. Dal Zotto, M. De Marchi, L. Gallo, P. Carnier, and G. Bittante. 2008. Genetic parameters for milk coagulation properties and their relationships with milk yield and quality traits in Italian Holstein Cows. J. Dairy Sci. 91:371-376.

Castillo, M., F. A. Payne, C. L. Hicks, J. Laencina, and M. B. Lopez. 2003. Effect of protein and temperature on cutting time prediction in goats' milk using an optical reflectance sensor. J. Dairy Res. 70:205-215.

Curley, D. M., T. F. Kumosinski, J. J. Unruh, and H. M. Farrell Jr. 1998. Changes in the secondary structure of bovine casein by Fourier transform infrared spectroscopy: Effects of calcium and temperature. J. Dairy Sci. 81:3154-3162.

Dalgleish, D. G. 1980. Effect of milk concentration on the rennet coagulation time. J. Dairy Res. 47:231-235.

De Marchi, M., R. Dal Zotto, M. Cassandro, and G. Bittante. 2007. Milk coagulation ability of five dairy cattle breeds. J. Dairy Sci. 90:3986-3992.

Etzion, Y., R. Linker, U. Cogan, and I. Shmulevich. 2004 Determination of protein concentration in raw milk by midinfrared Fourier transform infrared/attenuated total reflectance spectroscopy. J. Dairy Sci. 87:2779-2788.

Fagan, C. C., M. Castillo, C. P. O’Donnell, D. J. O'Callaghan, and F. A. Payne. 2008. On-line prediction of cheese making indices using backscatter of near infrared light. Int. Dairy J. 18:120-128.

Fagan, C. C., C. Everard, C. P. O’Donnell, G. Downey, E. M. Sheehan, C. M. Delahunty, and D. J. O'Callaghan. 2007. Evaluating midinfrared spectroscopy as a new technique for predicting sensory texture attributes of processed cheese. J. Dairy Sci. 90:11221132

Formaggioni, R., M. Malacarne, A. Summer, E. Fossa, and P. Mariani. 2001. Milk with abnormal acidity. The role of phosphorus content and the rennet-coagulation properties of Italian Friesian herd milk. Ann. Fac. Med. Vet. University of Parma 21:261-268.

Foss. 2007. MilkoScan FT120. http://www.foss.dk/Solutions/ ProductsDirect/MilkoScan FT120.aspx. Accessed Jan. 26, 2007. Foss Electric, Hillerød, Denmark.

Haaland, D. M., and E. V. Thomas. 1988. Partial least squares methods for spectral analyses. 1. Relation to other quantitative calibration methods and extraction of qualitative information. Anal. Chem. 60:1193-1202.

Heuer, C., H. J. Luinge, E. T. G. Lutz, Y. H. Schukken, J. H. van der Maas, H. Wilmink, and J. P. T. M. Noordhuizen. 2001. Determination of acetone in cow milk by Fourier transform infrared spectroscopy for the detection of subclinical ketosis. J. Dairy Sci. 84:575-582.

Hewavitharana, A. K., and B. V. Brakel. 1997. Fourier transform infrared spectrometric method for rapid determination of casein in raw milk. Analyst (Lond.) 122:701-704.
ICAR. 2006. International Committee for Animal Recording. Guidelines approved by the General Assembly held in Kuopio, Finland, on June 9 2006. ICAR, Paris, France.

Ikonen, T. 2000. Possibilities of genetic improvement of milk coagulation properties of dairy cows. PhD Diss. Univ. Helsinki, Finland. Available: http://ethesis.helsinki.fi/julkaisut/ maa/kotie/ vk/ikonen.

Ikonen, T., K. Ahlfors, R. Kempe, M. Ojala, and O. Ruottinen. 1999. Genetic parameters for the milk coagulation properties and prevalence of noncoagulating milk in Finnish dairy cows. J. Dairy Sci. 82:205-214.

Ikonen, T., A. Morri, A.-M. Tyrisevä, O. Ruottinen, and M. Ojala. 2004. Genetic and phenotypic correlations between milk coagulation properties, milk production traits, somatic cell count, casein content and pH of milk. J. Dairy Sci. 87:458-467.

Ikonen, T., M. Ojala, and E.-L. Syväoja. 1997. Effects of composite casein and beta-lactoglobulin genotypes on renneting properties and composition of bovine milk by assuming an animal model. Agric. Food Sci. Finland 6:283-294

ISO (International Organization for Standardization). 1994a Accuracy (trueness and precision) of measurement methods and results-Part 1: General principles and definitions. ISO 57251. International Organization for Standardization, Geneva, Switzerland.

ISO (International Organization for Standardization). 1994b. Accuracy (trueness and precision) of measurement methods and results-Part 1: Basic method for the determination of repeatability and reproducibility of a standard measurement method. ISO 5725-2. International Organization for Standardization, Geneva, Switzerland.

Karoui, R., A. M. Mouazen, E. Dufour, L. Pillonel, D. Picque, J. De Baerdemaeker, and J.-O. Bosset. 2006. Application of the MIR for the determination of some chemical parameters in European Emmental cheeses produced during summer. Eur. Food Res. Technol. 222:165-170.

Kübarsepp, I., M. Henno, H. Viinalass, and D. Sabre. 2005. Effect of k-casein and B-lactoglobulin genotypes on the milk rennet coagulation properties. Agric. Res. 3:55-64.

Lefèvre, T., and M. Subirade. 2000. Interaction of B-lactoglobulin with phospholipids bilayers: A molecular level elucidation as revealed by infrared spectroscopy. Int. J. Biol. Macromol. 28:59-67.

Lindström, U. B., V. Antila, and J. Syväjärvi. 1984. A note on some genetic and non-genetic factors affecting clotting time of Ayrshire milk. Acta Agric. Scand. 34:349-355.

Luginbühl, W. 2002. Evaluation of designed calibration samples for casein calibration in fourier transform infrared analysis of milk. Lebensm. Wiss. Technol. 35:554-558.

Lynch, J. M., D. M. Barbano, M. Schweisthal, and J. R. Fleming. 2006. Precalibration evaluation procedures for mid-infrared milk analyzers. J. Dairy Sci. 89:2761-2774.

Mariani, P., G. Losi, V. Russo, G. B. Castagnetti, L. Grazia, D. Morini, and E. Fossa. 1976. Cheesemaking trials with milk characterized by $\mathrm{K}$-casein $\mathrm{A}$ and $\mathrm{B}$ variant in the production of the ParmigianoReggiano cheese. Sci. Tecn. Latt. Cas. 27:208-227.

Martens, H., and T. Naes. 1989. Models for calibration. Chapter 3 in Multivariate Calibration. H. Martens and T. Naes, ed. John Wiley \& Sons Ltd., London, UK.

Paulsen, M. R., and M. Singh. 2004. Calibration of a near-infrared transmission grain analyser for extractable starch in maize. Biosystems Eng. 89:79-83.

Politis, I., and K. F. Ng-Kwai-Hang. 1988. Effect of somatic cell counts and milk composition on the coagulating properties of milk. J. Dairy Sci. 71:1740-1746.

SAS Institute. 2001. SAS User's Guide: Statistics. Release 8.2. SAS Institute, Inc., Cary, NC.

Sinnaeve, G., P. Dardenne, R. Agneessens, and R. Biston. 1994. The use of near infrared spectroscopy for the analysis of fresh grass silage. J. Near Infrared Spectrosc. 2:79-84.

Soyeurt, H., P. Dardenne, F. Dehareng, G. Lognay, D. Veselko, M. Marlier, C. Bertozzi, P. Mayeres, and N. Gengler. 2006. 
Estimating fatty acid content in cow milk using Mid-infrared Spectrometry. J. Dairy Sci. 89:3690-3695.

Summer, A., P. Formaggioni, F. Tosi, E. Fossa, and P. Mariani. 1999. Effects of the hot-humid climate on rennet-coagulation properties of milk produced during summer of 1998 and relationship with the housing systems in the rearing of Italian Friesian cows. Ann. Fac. Med. Vet. Univ. Parma 19:167-179.

Summer, A., M. Malacarne, F. Martuzzi, and P. Mariani. 2002. Structural and functional characteristics of Modenese cow milk in Parmigiano-Reggiano cheese production. Ann. Fac. Med. Vet. Univ. Parma 22:163-174.

Tervala, H.-L., V. Antila, and J. Syväjärvi. 1985. Factors affecting the renneting properties of milk. Meijeritieellinen Aikakauskirja XLIII:16-25.
Tyrisevä, A.-M., T. Vahlsten, O. Ruottinen, and M. Ojala. 2004 Noncoagulation of milk in Finnish Ayrshire and HolsteinFriesian cows and effect of herds on milk coagulation ability. J. Dairy Sci. 87:3958-3966.

Williams, P. 2003. Near-infrared technology getting the best out of light. Page 109 in A Short Course in the Practical Implementation of Near Infrared Spectroscopy for the User. 1.1 ed. PDKProjects Inc., Nanaimo, Canada.

Williams, P., and K. Norris. 2001. Near-Infrared Technology in the Agricultural and Food Industries. American Association of Cereal Chemists, St. Paul, MN. 